\title{
INTEGRAÇÃO E DIFERENÇA EM ENCONTROS DISCIPLINARES*
}

\section{Myrian Sepúlveda dos Santos}

\section{Introdução}

O tema da interdisciplinaridade é cada vez mais debatido no meio acadêmico. Os organizadores do encontro da SBPC em 2006, cujo título foi "Semear a Interdisciplinaridade", procuraram não só intensificar o debate sobre o tema, mas incentivar a formação de grupos de trabalho com especialistas de diferentes campos disciplinares. O ponto de partida do encontro foi o diagnóstico de que a progressiva especialização nas variadas

* Agradeço a Rosane Prado, Hector Leis e Frederic Vandenbergue a leitura cuidadosa e os comentários a este texto, inicialmente apresentado na mesa redonda "Limites e Trânsitos Interdisciplinares nas Ciências Sociais Hoje", Anpocs, 2006.

Artigo recebido em novembro/2006 Aprovado em setembro/2007 áreas do conhecimento pode levar a uma visão retalhada e incompleta do mundo. Questões relacionadas à nanotecnologia, à biodiversidade, ao mapa genético ou à criminalidade, por exemplo, não são mais respondidas com base em marcos disciplinares já estabelecidos. Na área das ciências sociais, o debate é também muito intenso. Em duas publicações recentes, há a preocupação em ultrapassar as limitações da especialização crescente do conhecimento e fronteiras disciplinares. ${ }^{1}$

O que presenciamos, hoje, portanto, é um movimento inverso àquele responsável pela fragmentação do mundo em campos disciplinares, ou seja, a tentativa de que esses campos se comuniquem, permitindo a formação de um conhecimento mais adequado às necessidades de intervenção prática, política e social. Ao reduzirem a complexidade do mundo real, as diversas disciplinas enfrentam impasses na compreensão e na explicação de seus objetos, bem como no desenvolvimento e na aplicação de suas descobertas. Cabe ressaltar, 
nesse sentido, a advertência de Bruno Latour sobre a separação moderna entre ciências exatas, biológicas e humanas. Ao levantar questões relacionadas com aquecimento global, poluição, camada de ozônio e aumento demográfico, cujos temas são híbridos e envolvem natureza e cultura, o autor se pergunta: Em que campo do conhecimento devemos abrigar tais temas? Na biologia, na sociologia, na história natural, na sociobiologia? (Latour, 1991, pp. 72-73). Entretanto, apesar do foco crescente na interdisciplinaridade, não se observa no campo científico um aumento significativo de pesquisas interdisciplinares.

Há dois aspectos que precisam ser enfatizados para compreendermos as dificuldades relativas ao estabelecimento de novas abordagens. Em primeiro lugar, o conhecimento está organizado sob formas disciplinares nas diversas instituições de pesquisa. A relação de poder e prestígio entre a pesquisa disciplinar e a interdisciplinar não é homogênea. Aqueles que trabalham em consonância com as fronteiras disciplinares consagradas raramente acham necessário ter mais do que uma noção aproximada da linguagem, dos princípios e dos conceitos defendidos pelos que trabalham de forma interdisciplinar. Eles só precisam se adaptar aos comitês de avaliação, distribuição de recursos, seleção de recursos humanos, bem como aos diversos meios de divulgação já existentes. Em contrapartida, pesquisadores que optam pela interdisciplinaridade necessitam aprender a linguagem e a cultura das diversas disciplinas, mesmo aquelas que se situam fora de seu campo de interesse. Abordagens interdisciplinares, como é o caso dos recentes estudos feministas, têm maior dificuldade de obter legitimidade em departamentos e instituições acadêmicas e raramente se constituem em prioridades para o investimento econômico das instituições a que pertencem.

O segundo aspecto a ser ressaltado ocorre no plano teórico, pois as pesquisas que se localizam na fronteira entre uma ou mais disciplinas não só desafiam o conhecimento disciplinar estabelecido, como também necessitam estabelecer novos paradigmas para o conhecimento. Nem sempre, entretanto, encontramos nas novas abordagens interdisciplinares definições conceituais claras de objeto e metodologia.
O objetivo deste artigo é aprofundar alguns aspectos relativos aos impasses teóricos relacionados à interdisciplinaridade. Como ponto de partida desta reflexão tenho por base minha experiência profissional - como membro de um programa de pós-graduação que se autodefine como interdisciplinar e editora de uma revista também de cunho interdisciplinar - e minha carreira acadêmica, que, embora inicialmente calcada nas premissas da teoria sociológica, foi se aproximando gradativamente das opções oferecidas por outros campos do conhecimento. ${ }^{2}$

A análise de Thomas Kuhn sobre a estrutura das revoluções científicas tornou-se uma referência obrigatória para este debate, não só porque ele apontou a dinâmica e a evolução da ciência a partir da substituição de paradigmas, mas também porque rejeitou a relação direta entre conhecimento e realidade (Kuhn, 1987). Segundo o autor, as disciplinas científicas são constituídas historicamente por um paradigma, isto é, um conjunto de regras, princípios e instrumentos que permitem entender e classificar fenômenos dentro de uma determinada visão de mundo.

Embora o ponto de partida deste artigo seja o de que projetos sociais e políticos se relacionam às demandas da sociedade, é importante reconhecer a crítica feita por Kuhn à relação direta que se faz entre uma ciência positiva e o mundo real. As transformações ocorridas nos diversos campos do saber têm ritmos e especificidades diversas e no que tange ao conhecimento acadêmico seu desenvolvimento tem características próprias. A especialização do saber da forma que conhecemos hoje tem uma clara demarcação no século XVIII e corresponde a uma série de fenômenos apontados pelos grandes pensadores do início do século XX. Acreditava-se que a crescente divisão do trabalho, da racionalidade, da burocracia e dos processos de individualização eram aspectos oriundos do desenvolvimento, da evolução ou progresso da humanidade.

O saber acadêmico e institucionalizado organizou-se com base na separação entre natureza e cultura. A explicação de fenômenos da natureza passou a ser dada a partir da observação empírica e de métodos indutivos claros. A redução e a fragmentação da realidade tiveram como objetivo proporcionar conhecimentos cada vez mais espe- 
cíficos e precisos sobre os objetos estudados. A cisão entre natureza e cultura, portanto, permitiu a formação de uma racionalidade científica que inicialmente se voltou para os fenômenos da natureza, mas, logo em seguida, se expandiu para o campo da Biologia e das atividades humanas.

Alguns autores trouxeram para as ciências sociais os métodos utilizados na explicação de fenômenos da natureza, e os acontecimentos sociais passaram a ser conceituados em bases rígidas e comparados entre si. Regularidades, funções e estruturas foram ressaltadas. Concomitantemente, a abordagem histórico-hermenêutica foi defendida como base do conhecimento aplicado às humanidades. Negava-se, neste caso, o distanciamento entre pesquisador e objeto e defendia-se o conhecimento derivado da proximidade e empatia existentes entre ambos. O caráter científico continuava a existir, sendo dessa vez derivado do rigor do método interpretativo aplicado. Em ambos os casos, rejeitava-se a existência de afinidades entre a espécie humana e outros seres vivos.

Embora a compartimentalização do conhecimento jamais tenha alcançado consenso no interior do debate permanente acerca dessa questão, atualmente ela tem sido alvo de críticas mais duras. A primeira das grandes fronteiras estabelecidas pela ciência, aquela entre natureza e cultura, tem sido cada vez mais questionada. De um lado, ativistas dos diversos movimentos ecológicos e da luta pela paz, dos movimentos feministas, pós-colonialistas e tantos outros repudiam a racionalidade do Ocidente, considerada opressora, e resgatam novas dimensões relacionadas à espécie humana, como pulsões, sentimentos e emoções irredutíveis à razão. De outro lado, novas descobertas científicas, como aquelas relacionadas à manipulação da herança genética, tornam evidente a impossibilidade da separação entre cientificidade e moralidade. ${ }^{3}$

Diante desse movimento progressivo na direção de um maior diálogo entre diferentes campos disciplinares, surge a necessidade de estabelecermos alguns critérios que facilitem a compreensão do lugar do qual falamos. Embora o termo interdisciplinaridade possa ser utilizado para indicar diferentes formas de complementaridade e integração entre disciplinas, os termos multidisciplinaridade, interdisciplinaridade e transdiscipli- naridade têm sido cada vez mais utilizados para indicarem de modo mais específico as diferentes formas e graus de comunicação entre disciplinas, isto é, domínios do conhecimento. Eles serão adotados ao longo do texto como indicação de horizontes possíveis de diálogo a serem respeitados.

\section{Multidisciplinaridade: o encontro entre monólogos disciplinares}

O prefixo "multi", derivado do latim, indica que algo se apresenta de forma numerosa, em abundância e profusão. Por multimídia, por exemplo, compreendemos a combinação de diferentes formas de comunicação - sons, imagens, textos - em um único sistema. Multidisciplinaridade, portanto, pode ser um termo utilizado para indicar pesquisas de campos disciplinares distintos, os quais, no entanto, se unem em torno de um objetivo comum. As fronteiras disciplinares são mantidas; a forma de trabalho em conjunto é complementar e não visa à formulação de conceitos unificados; os resultados das pesquisas são integrados, mas não o processo de investigação do objeto. Projetos multidisciplinares, portanto, são aqueles que apontam para uma colaboração entre pesquisadores de diferentes disciplinas, sem que um novo aparato conceitual seja discutido. Diferentes especialistas desenvolvem investigações e análises com base nos princípios estabelecidos por suas disciplinas, sem que se estabeleçam diálogos e trocas conceituais ou metodológicas entre eles.

Os especialistas em nanotecnologia, por exemplo, sem abrirem mão de seus princípios metodológicos e conceituais, precisam cada vez mais do conhecimento da biologia ou da medicina, para que o conhecimento adquirido possa ser aplicado no combate a doenças, na produção de alimentos e assim por diante. Da mesma forma, podemos dizer que a engenharia ambiental necessita cada vez mais do conhecimento da antropologia sobre populações nativas para que a aplicação do monitoramento e do controle ambiental possa se efetivar. Estes são apenas alguns exemplos da necessidade crescente de comunicação entre campos disciplinares. 
O Programa de Pós-Graduação em Meio Ambiente da UERJ (PPG-MA) foi criado segundo um formato multidisciplinar. Participam deste programa os profissionais dos Institutos de Biologia, Química, Física, e Geociências; das Faculdades de Engenharia, Tecnologia, Direito e Educação; e dos Institutos de Medicina Social e Filosofia e Ciências Humanas. Física, Antropologia, Engenharia e outros campos de saber também são áreas complementares no sentido de formar profissionais que tenham noção dos diferentes paradigmas disciplinares e que, a partir desse conhecimento, sejam mais eficientes na resolução de problemas gerados em torno da questão ambiental. O curso "foi estruturado com o objetivo de organizar, sistematizar e consolidar um locus de formação de recursos humanos que atendam às demandas impostas por uma agenda atenta às questões socioambientais". Mas é evidente que as análises devem ser efetuadas a partir da referência de cada especialista. Se as demandas de cooperação relativas às questões socioambientais não estiverem claras para todos os componentes do grupo, o curso corre o risco de propiciar apenas abordagens generalistas sobre diversos campos do saber. Os criadores de uma teoria da evolução ou de uma bomba atômica podem estar mais cientes ou não das implicações políticas, morais e sociais de sua criação, mas tal conhecimento não será constituinte do processo de pesquisa. Ele é fundamental à aplicação da invenção. Encontros multidisciplinares, portanto, pressupõem a cooperação na aplicação de seus conhecimentos, que devem ser adquiridos, entretanto, em cada campo disciplinar.

O respeito a um campo disciplinar mais distante é relativamente fácil, uma vez que nenhum dos pesquisadores detém conhecimento suficiente para questionar as bases conceituais do parceiro com que trabalha. Apesar de os profissionais das áreas de engenharia e antropologia, por exemplo, trabalharem em um mesmo projeto, objetivando a união dos resultados das pesquisas, até mesmo as fronteiras entre natureza e cultura são respeitadas com mais facilmente. Mas como veremos adiante, quando os campos disciplinares são muito próximos, o respeito às fronteiras já estabelecidas se torna mais problemático. Nesse caso, a possibilidade de questionamento é maior, o que pode acarretar competição, insegurança e ressentimento.

\section{Interdisciplinaridade: o diálogo constituído entre disciplinas diferentes}

É relativamente freqüente nas ciências sociais a integração entre disciplinas próximas, que passam a se constituir como um novo campo disciplinar. Diferentemente da pesquisa multidisciplinar, a interdisciplinar parte da integração de uma ou mais disciplinas em uma nova abordagem, com a conseqüente construção de seus próprios objetos, conceitos, premissas e paradigmas. O prefixo "inter", também derivado do latim, indica uma posição intermediária, de interação ou reciprocidade. Não se trata mais de combinar pesquisas com métodos e conceitos diferentes, mas de construir um novo aparato conceitual e metodológico na explicação ou interpretação de um novo objeto. Nesta fusão, pode haver predominância ou não de uma das disciplinas envolvidas. Os exemplos são inúmeros, e alguns deles serão examinados a seguir.

As ciências humanas, em geral, ou as ciências sociais, em particular, partem da crença de que por meio da racionalidade científica o pesquisador é capaz de captar a essência do mundo real. Seus artífices, então, reduzem ou simplificam a realidade para encontrar nela constantes que possam auxiliar a compreensão e a explicação do que acontece na vida real. Que constantes são estas? Ação social, mudança, evolução, desenvolvimento, fato social, estrutura, sistema, interação, processo, práxis, habitus, campo e assim por diante. Tais conceitos reduzem uma realidade complexa a um vetor-chave capaz de explicar os aspectos centrais e mais relevantes do que se observa, como, por exemplo, organizações sociais, hierarquias, disputas, discriminação e exclusão, instituições e guerras. Em alguns casos, essa redução é feita a partir de um campo disciplinar, em outros, ela ocorre a partir de um instrumental teórico mais amplo, que incorpora um ou mais campos disciplinares.

Apesar da crença comum na cientificidade das abordagens realizadas, diferentemente do que ocorre nas ciências exatas, o distanciamento entre o pesquisador e seu objeto nas ciências humanas envolve uma tensão permanente, sendo o confronto entre abordagens explicativas e interpreta- 
tivas insolúvel e duradouro. Dividem-se, ainda, as disciplinas pela forma como os pesquisadores percebem o tempo, priorizando ou as concepções sincrônicas ou as diacrônicas (Hall, 1980). Para melhor compreendermos os impasses teóricos resultantes de encontros disciplinares nas ciências sociais, minha análise partirá da sociologia, disciplina que, talvez por sua maior dificuldade de definição do objeto, tem se caracterizado por um maior debate teórico. Entretanto, é evidente que as mesmas tensões apontadas no campo sociológico estão presentes entre antropólogos, historiadores e cientistas políticos.

Inegavelmente foi Émile Durkheim quem estabeleceu as fronteiras mais claras e rígidas da sociologia como campo disciplinar. Como sabemos, suas três primeiras obras, escritas no curto espaço de quatro anos, estabeleceu os paradigmas centrais da disciplina (Durkheim, 1897, 1967a, 1967b). De forma extremamente simplificada, podemos dizer que, para o grande pensador, tratava-se de definir os fatos sociais ou morais, ou seja, crenças, valores e sentimentos coletivos como o grande objeto das ciências sociais. Cientificamente, seria possível reconhecer, observar, descrever, classificar e explicar os padrões de comportamento e pensamentos coletivos, considerados como sendo os grandes determinantes da conduta humana.

Não obstante a influência significativa de Durkheim na consolidação da sociologia, suas teses também foram determinantes tanto para antropólogos como para historiadores. O recorte disciplinar, neste caso, estabelecia-se em função da opção pela metodologia e definição do objeto. Enquanto sociólogos se uniam a estatísticos procurando aprimorar os métodos quantitativos capazes de serem utilizados na comparação de padrões de comportamento inerentes a grandes coletividades, antropólogos se voltavam para a etnografia como forma de investigação de relações sociais que podiam ser observadas empiricamente. Historiadores, por sua vez, perdiam o interesse em grandes heróis, guerras e batalhas, procurando construir uma abordagem científica mediante a análise de longas permanências sociais, geográficas e mentais. Em todas essas abordagens, encontramos uma busca sistemática das estruturas que seriam capazes de se perpetuarem em temporalidades distintas. As noções de causalidade histórica, movimento e mudança foram substituídas por aquelas que apontavam regularidades e rupturas estruturais.

Críticas contundentes foram dirigidas à abordagem durkheimiana desde seus primórdios, uma vez que ela não explicava processos e transformações histórico-sociais, nem tampouco a variabilidade inerente aos fatos sociais. Por mais influentes que fossem, as abordagens estruturais e funcionalistas jamais alcançaram o consenso desejado. Pelo menos duas outras correntes teóricas partilharam o campo que se formava. De um lado, podemos destacar a ênfase dada ao papel desempenhado pelo ator social e o reconhecimento do caráter processual do tempo nos trabalhos deixados por Max Weber. Como sabemos, o pensador alemão consolidou a abordagem compreensiva nas ciências sociais, ao conferir aos atores sociais a responsabilidade pela produção das estruturas sociais, políticas e econômicas, em um estudo cuidadoso e não generalizante sobre o nascimento do capitalismo na Europa Ocidental. De outro lado, os trabalhos de Simmel, na Alemanha, e de George-Herbert Mead, nos Estados Unidos, trouxeram para o campo das ciências sociais um novo foco de análise, qual seja, os processos interativos ocorridos em contextos empiricamente observáveis.

O debate acirrado entre as diferentes perspectivas teóricas, cada uma delas reivindicando apenas para si o caráter de cientificidade no campo das humanidades, foi parcialmente apaziguado nos anos de 1950, a partir do trabalho de Talcott Parsons. Coube a esse autor não só esboçar a primeira tentativa de síntese teórica entre concepções que privilegiavam a ação e a estrutura social, movimento este contemporaneamente desenvolvido por outros autores, mas também estabelecer uma divisão disciplinar que melhor acomodasse os debates da época.

Parsons desenvolveu uma análise estruturalfuncionalista com o objetivo de compreender de forma inclusiva todos os aspectos relacionados à "ação social", conceito até então minimizado pela teoria durkheimiana. A ação social foi analisada por meio de seu funcionamento e de suas modalidades sistêmicas. No que tange à análise funcional, Parsons destacou quatro imperativos funcio- 
nais inerentes às ações sociais, a saber, necessidade de adaptação do organismo ao meio externo; realização de objetivos e metas mediante motivação e orientação dos agentes sociais; integração dos atos sociais, por meio de controle, coordenação e formas de solidariedade; e, por fim, manutenção de padrões de comportamento constituídos pelos elementos simbólicos. A esses imperativos funcionais, o autor relacionou quatro elementos estruturais ou sistemas: biológicoadaptativo, psíquico-instrumental, social e cultural-expressivo. Conferiu ainda dinâmicas e movimentos diferenciados a cada um desses subsistemas, atribuindo maior estabilidade ao sistema cultural, que seria mais rico em informação, desempenharia o papel de controle da ação e seria de difícil mudança e menor estabilidade ao sistema orgânico e adaptativo, menos estável e mais apto a mudanças (Parsons e Shils, 1951; Parsons et al., 1953).

A influência de Parsons no campo acadêmico tem sido reportada por especialistas dos diversos campos disciplinares. O que merece ser destacado nesta análise é que a teoria geral da ação proposta por ele foi muito importante na organização disciplinar, na medida em que vinculou determinadas abordagens teóricas a campos disciplinares específicos. ${ }^{4} \mathrm{~A}$ antropologia foi relacionada aos estudos sobre cultura, mais especificamente a perspectivas que privilegiavam valores, idéias e permanências. Os estudos das estruturas e dos papéis sociais caberiam aos sociólogos; aqueles voltados para as motivações, os processos e as transformações históricas, à ciência política, e questões materiais de produção e sobrevivência, aos economistas. Este esquema inegavelmente apontou e organizou divisões existentes nas ciências humanas, uma vez que podemos observar ainda hoje a ênfase dada por cientistas políticos às teorias da ação, sendo os antropólogos, principalmente os norte-americanos, mais atraídos por abordagens culturalistas. Ainda assim é evidente que a teoria parsoniana não foi capaz de ultrapassar os confrontos teóricos delineados acima, que permaneceram tanto no interior de cada divisão disciplinar, como nas fronteiras estabelecidas entre as disciplinas.

Em meio a tantas tensões teóricas na formulação de objeto, métodos e conceitos, é com- preensível o elevado índice de encontros e formações interdisciplinares no campo das ciências sociais. Tentativas de síntese teórica que agregam ação e estrutura, micro e macroabordagens, continuidades e descontinuidades foram formuladas por autores como Norbert Elias, Anthony Giddens e Pierre Bourdieu. Novos conceitos, como os de configuração, estruturação ou campo e habitus, são inegavelmente mais abrangentes do que os anteriores, uma vez que contemplam a ação social, mas também seus limites. Esses autores exercem influência em diferentes campos disciplinares. De qualquer forma, tais abordagens ainda não respondem a questões essenciais. A ênfase em continuidade ou descontinuidade temporal, de um lado, e, entre interação e sistemas, de outro, continuam a demarcar fronteiras.

A fronteira entre sociologia e história é compreendida por muitos com base na divisão entre passado e presente. Qualquer análise um pouco mais aprofundada, entretanto, percebe que, de um lado, não é possível analisarmos o presente sem as determinações do passado, e, de outro, qualquer abordagem ao passado é influenciada pelos interesses e disputas do presente. Alguns outros critérios foram procurados para estabelecer a fronteira disciplinar, como a atribuição à história da reconstrução detalhada do passado, com base em documentos e evidências materiais, e à sociologia a formação de leis generalizantes e universais. Tais conceituações mantêm-se problemáticas, pois não satisfazem os especialistas de nenhuma destas áreas. Historiadores, tal como os sociólogos, vêem-se divididos pelas antinomias entre ação e estrutura, explicação e compreensão, continuidade e descontinuidade temporal. Além dessas divisões, ainda há aquelas causadas pela opção por macro e microabordagens (Dosse, 1987).

Em meio a tantas questões, é compreensível não só a fragilidade em que se encontram as fronteiras estabelecidas, mas também a tendência a reformulações e novas definições de campos e fronteiras disciplinares. A interdisciplinaridade, portanto, constitui-se justamente nesse contexto. Alguns dos encontros entre disciplinas diferentes integraram-se de tal forma que acabaram por constituir novos campos disciplinares, com objeto, métodos e conceitos próprios. Sociologia histórica, antropologia social, sociologia política, psi- 
cologia social e política econômica são alguns exemplos nesse sentido. O sucesso na construção de um campo implica a formação de especialistas, redes de pesquisa, status institucional, apoio econômico e meios de divulgação próprios.

A convivência entre disciplinas próximas, no entanto, não é pacífica. Sob a primazia do mito da racionalidade científica, cada campo disciplinar que se constitui procura se sobrepor aos demais, desqualificando seus oponentes. No caso da sociologia histórica, por exemplo, que tem por base os estudos de Max Weber, a dificuldade de validade acadêmica não parece ser grande (Sztompka, 1998, pp. 345-360). Autores como Charles Tilly e Theda Skockpol definiram como seu novo objeto as continuidades inerentes a movimentos sociais, mecanismos inerentes a ações coletivas, transformações e revoluções sociais, rejeitando explicações marxistas, esquemas rígidos e leis universais da história. A defesa da nova disciplina pode alcançar versões radicais. Para Philip Abrams, por exemplo, a sociologia histórica, voltada para a compreensão de processos sociais, é a única abordagem capaz de ultrapassar as antinomias entre atividade humana e estruturação social, de um lado, e entre temporalidade diacrônica e sincrônica, de outro, e por essa razão deveria substituir as demais correntes teóricas (Abrams, 1982).

Já os historiadores voltados para uma abordagem mais subjetiva e contingente encontram maior dificuldade em legitimar-se junto a seus pares. A história oral e a história de vida configuram-se em um novo campo disciplinar criado com base na confiança mútua entre pesquisador $\mathrm{e}$ informante, e tendo por objetivo possibilitar ao pesquisador a utilização de fontes não validadas pela historiografia precedente.

A psicologia social é um outro exemplo de encontro interdisciplinar. Ao se constituir como alternativa teórica no campo das ciências sociais, tornou-se uma nova abordagem disciplinar, estabelecendo um novo objeto - as interações sociais empiricamente observadas - e criticando os limites disciplinares das abordagens até então estabelecidas. Ulric Neisser, autoridade no conhecimento de falhas e de outros fenômenos relativos à memória, não teve nenhum problema em afirmar que a psicologia experimental praticamente nada tinha descoberto sobre o tema. Segundo ele, os testes utili- zados para determinar as capacidades individuais de memorização e esquecimento, realizados há mais de cem anos, continuavam a ser reproduzidos sem nenhum avanço. As experiências de laboratório não poderiam explicar "para que" ou "como" as pessoas se lembravam do passado. Apenas a nova abordagem, com diferentes objeto e método de pesquisa poderia responder questões realmente importantes sobre o funcionamento da memória (Neisser, 1982, pp. 6-12).

Assim sendo, o encontro entre disciplinas pode ter como resultado a constituição de um novo campo de conhecimento, com um aparato conceitual próprio, consolidado entre pares e com reflexos substanciais no formato institucional. Mas cabe novamente ressaltar que esses encontros, em permanente configuração, podem levar à disputa, à intransigência e à falta de respeito entre profissionais de disciplinas próximas. Coloca-se em cheque a capacidade de uma determinada abordagem de contribuir para o conhecimento dos fenômenos sociais. Aceitar o diferente só é possível quando a integridade de quem aceita o "outro" não está em jogo.

O Programa de Pós-Graduação em Ciências Sociais (PPCIS/UERJ) tem como objetivo formar especialistas em ciências sociais, ou seja, com conhecimento nas três áreas disciplinares - antropologia, sociologia e ciência política. Apesar de ser denominado um programa interdisciplinar, ele opera com fronteiras bem marcadas entre as disciplinas, sendo próximo à conceituação de funcionamento multidisciplinar. Nos fóruns coletivos de avaliação de projetos os impasses são muitos. Os antropólogos, por exemplo, têm severas objeções à naturalização de objetos, conceitos e classificações em uma pesquisa; eles não abrem mão de uma postura que, a princípio, coloque em suspenso as afirmativas e as classificações do senso comum. Em contrapartida, sociólogos e cientistas políticos que trabalham com análises quantitativas não só fazem largo uso de classificações dadas, como também trabalham a partir de hipóteses, antecipação de resultados e definições metodológicas. Para estes, a ausência de hipóteses a serem comprovadas e de uma metodologia bem defini$\mathrm{da}$, aspectos comuns nos projetos direcionados à área antropológica, impossibilita uma investigação científica. Há, ainda, uma terceira perspectiva, 
histórica e interpretativa, que, embora aceita, é invariavelmente desqualificada como estando "fora do lugar" pelas demais abordagens. Como cada uma dessas abordagens não é capaz de superar as demais, as desqualificações teóricas feitas por membros de um campo disciplinar a outro se constituem em meio à arrogância e ao ressentimento, emoções que permeiam as relações sociais entre intelectuais.

Como vimos, o tema da interdisciplinaridade faz parte da consolidação do campo científico moderno, cuja premissa básica é a possibilidade de distanciamento ou hierarquia entre o pesquisador e seu objeto. Os encontros descritos até então, sejam eles multidisciplinares e monológicos ou interdisciplinares e dialógicos, produzem processos e resultados inerentes ao campo do conhecimento científico. À medida que os pesquisadores se distanciam desta premissa, eles se afastam não só do conceito de disciplina, mas também do de ciência. Estamos entrando, nesse sentido, na esfera da transdisciplinaridade.

\section{Transdisciplinaridade e o respeito à diferença em vozes polifônicas}

O terceiro prefixo latino utilizado para qualificar o encontro entre disciplinas, "trans", indica que há uma posição ou movimento "para além de". Pesquisas "transdisciplinares" procuram transcender as perspectivas disciplinares anteriores mediante a conceituação de novos objetos, concepções e métodos. Representam um desafio epistemológico às abordagens tradicionais. A conceituação de conhecimento é mais ampla do que as anteriores - questionam-se não só as antinomias já descritas, mas também a separação entre corpo e mente, práxis e poesis, consciente e inconsciente. Perspectivas disciplinares são integradas a abordagens não disciplinares, e o mundo do conhecimento deixa de estar condicionado apenas à razão e à lógica, passando a ser também aquele da estética, da poesia e do imaginário. A neutralidade do conhecimento científico é colocada em questão. Para as perspectivas disciplinares tradicionais, as novas abordagens transdisciplinares são consideradas ilegítimas, transgressivas e inconsistentes.
Embora Karl Marx e Sigmund Freud se voltem para o controle do devir histórico e da psique por intermédio da razão científica moderna, eles formularam conceitos que permitem a crítica interna ao projeto em que se inserem. A premissa de uma visão dialética da história é a de que a superação dos contrários ocorre na práxis social, ou seja, para Marx o conhecimento não se separa da perspectiva de revolucionar o mundo. O saber não foi compreendido apenas nos marcos da razão, uma vez que estava condicionado à luta de classes. Em Freud, o conceito de inconsciente destrói a possibilidade de um conhecimento empírico e lógico que não tenha ligação com o irracional, trazendo para dentro do campo científico elementos determinantes que se baseiam em pulsões e emoções. O filósofo Michel Foucault, entretanto, foi aquele que formulou com maior rigor a crítica ao conhecimento moderno, associando-o ao poder. Sua obra exerce ainda hoje grande influência nos estudos contemporâneos, permitindo uma nova parceria entre intelectuais e projetos políticos e sociais. Para mulheres, negros, portadores de deficiências físicas, ambientalistas e cidadãos de países colonizados, a denúncia do efeito coercitivo de classificações e instituições, até então consideradas resultantes naturais do desenvolvimento e do progresso da humanidade, tem exercido um papel importante na luta destes grupos por emancipação. Os estudos deixados por Marx, Freud e Foucault, portanto, ao introduzirem conceitos como práxis, inconsciente e desejo pelo poder, respectivamente, são responsáveis pelo questionamento à associação naturalizada que fazemos entre conhecimento e verdade. Em todos os três casos, a natureza do conhecimento científico é colocada em questão. ${ }^{5}$

É muito conhecida a afirmação de Marx de que os homens fazem a sua própria história, mas não a fazem segundo a sua livre vontade. A antinomia entre ação e estrutura que está presente nos debates acadêmicos aparece em Marx (1982) como parte da dialética entre a práxis e as circunstâncias dadas e herdadas do passado. Assim, à medida que os pesquisadores procuram identificar a verdade ou a essência do que está em constante movimento, eles tornam estático, regular e sistemático o que é inconstante, contingente e imprevisível. Após tentar solucionar algumas das 
antinomias apresentadas aos cientistas sociais, o sociólogo polonês Zigmunt Bauman argumenta que os paradoxos existentes não devem ser superados, mas considerados em tensão. Criatividade e norma são conceitos que não podem ser dissociados, hierarquizados ou integrados - eles não são excludentes. Além disso, prossegue o autor, acatar os dois lados de uma moeda, sem reduzi-los um ao outro, ou mesmo, a um terceiro elemento, não implica em relativismo. O diagnóstico feito por este sociólogo sobre a ambivalência inerente à definição de cultura orienta em grande parte a reflexão aqui desenvolvida (Bauman, 1999).

É também de Bauman a observação de que a sociologia deveria ser entendida como uma entre as "numerosas narrativas, de muitos estilos e gêneros, que recontam, após terem primeiramente processado e reinterpretado, a experiência humana de estar no mundo". ${ }^{6}$ A sociologia, assim como o romance e muitas outras narrativas, contribui para o conhecimento, e não há nesta multiplicidade de olhares aquele que seja superior aos outros. Bauman desfaz a equação entre ciência e verdade ao assinalar que romances como os de Tolstói, Balzac, Dickens, Dostoiévski, Kafka ou Thomas Morus proporcionam mais insights sobre a substância das experiências humanas do que as centenas de relatórios de pesquisa sociológica. Para ele, diferentes narrativas podem contribuir para o conhecimento, ainda que de maneiras diversas. Todas elas podem ajudar a iluminar as respostas humanas à sua condição.

Muitos dos estudos feministas que operam nesta perspectiva transdisciplinar apontam omissões, hiatos, fraquezas e contradições em disciplinas tradicionais e propõem uma abordagem crítica, em que o conhecimento deve surgir a partir de uma nova forma de objetividade. A pesquisa, nesse sentido, deve dar visibilidade a elementos que não eram detectáveis nas formas anteriores de conhecimento. ${ }^{7}$ As feministas criticam a ciência estabelecida por ela ser organizada de modo a privilegiar atores sociais do gênero masculino. Assim, a forma pela qual o corpo é decomposto, as emoções avaliadas, as doenças problematizadas e o os papéis sociais definidos obedece a uma hierarquia de valores que é naturalizada. Esta é uma abordagem presente também em diversos estudos culturalistas que lidam com questões de raça, etnicidade e nacionalidade e que se integram tanto ao debate sobre construções de identidade, como à discussão acerca da desconstrução de formas de conhecimento que favorecem determinados atores em detrimento de outros na organização da sociedade (During, 1993).

Em suma, em contraste ao paradigma dominante disciplinar, a percepção de todo conhecimento como parcial é fundamental para a convivência entre diferentes abordagens teóricas. Esta observação é importante para a manutenção do respeito nos encontros multi, interou transdisciplinares. Nós nos confrontamos na pesquisa acadêmica com uma pluralidade de horizontes de conhecimento, irredutíveis e ambivalentes. A aquiescência à parcialidade do conhecimento leva o pesquisador a ser capaz de observar seu objeto como algo diferente, sendo que isso não é uma realidade capaz de ser reduzida nem por uma explicação, nem por uma interpretação definitiva, pois o objeto tem sua dinâmica própria. Portanto, o "outro", o "distante", é considerado também uma parte ativa na interação, sendo que nem ele mesmo aceita rótulo, classificação ou explicação dada pelo pesquisador, nem se revela inteiramente ao pesquisador, apesar de toda a empatia e a interação que possa ocorrer.

\section{BIBLIOGRAFIA}

ABRAMS, Philip. (1982), Historical sociology. Ithaca, Cornell University Press.

BAUMAN, Zigmunt. (1999), Culture as praxis. Londres/Thousand Oaks, Calif., Sage Publications.

COLLINS, Patricia Hill. (1990), Black feminist thought: knowledge, consciousness, and the politics of empowerment. Boston, Unwin Hyman.

DOSSE, François. (1987), L'histoire en miettes: des "Annales" à la "nouvelle bistoire". Paris, La Découverte.

DURING, Simon (org.). (1993), The cultural studies reader. Londres/Nova York, Routledge. 
DURKHEIM, Émile. (1897), Le suicide: étude de sociologie. Paris, F. Alcan.

(1967a), De la division du travail social. Paris, Presses Universitaires de France.

(1967b), Les règles de la métbode sociologique. Paris, Presses Universitaires de France.

HALL, John R. (1980), "The time of history and the history of times". History and Theory, 19 (2): 113-131.

(1997), Identidades culturais na pósmodernidade. Rio de Janeiro, DP\&A.

HARDING, Sandra. (1995), "Subjectivity, experience, and knowledge: an epistemology from/for rainbow coalition politics", in Judith Roof e Robin Wiegman (eds.), Who can speak? Authority and critical identity, Urbana, University of Illinois Press.

KUHN, Thomas. (1987), A estrutura das revoluções científicas. São Paulo, Perspectiva.

KUPER, Adam. (1973), Anthropologists and anthropology: the British school, 1922-1972. Londres, Allan Lane.

LATOUR, B. (1991), Nous n'avons jamais été modernes: essai d'anthropologie symétrique. Paris, La Découverte.

MARX, Karl. (1982), "O Dezoito Brumário de Luiz Bonaparte", in Karl Marx e Friedrich Engels, Obras escolbidas, Lisboa/Moscou, Avanti-Progresso.

NEISSER, Ulric. (1982), "What are the important questions?", in (ed.), Memory observed: remembering in natural contexts, San Francisco, W.H. Freeman.

PARSONS, T. \& SHILS, E. (1951), Toward a general theory of action. Cambridge: Harvard University Press.

PARSONS, T.; BALES, R. F. \& SHILS, E. A. (1953), Working papers in the theory of action. Glenco, IL, Free Press.
PORTO, Maria Stela Grossi \& DWYER, Tom (orgs.). (2006), Sociologia e realidade: pesquisa social no século XXI. Brasília, Editora da Universidade de Brasília.

SANTOS, José Vicente Tavares dos \& BAUMGARTEN, Maíra. (2006), "Editorial". Sociologias, 8 (15): 10-13.

SOPER, Kate. (1995), What is nature? Culture, politics, and the non-buman. Oxford/ Cambridge, Mass., Blackwell.

SZTOMPKA, Piotr. (1998), A sociologia da mudança social. Rio de Janeiro, Civilização Brasileira. 


\section{INTEGRAÇÃO E DIFERENÇA EM ENCONTROS DISCIPLINARES}

Myrian Sepúlveda dos Santos

Palavras-chave: Interdisciplinaridade; Epistemologia; Teoria social; Sociologia.

A ciência constrói seus objetos com base em propostas de conhecimento que podem ser relacionadas a projetos sociais e políticos. Embora pesquisas interdisciplinares respondam a demandas crescentes da sociedade, elas encontram dificuldades, tanto por desafiarem o conhecimento disciplinar estabelecido, como por necessitarem de novos paradigmas para o conhecimento, o que muitas vezes não ocorre. Os limites estabelecidos por cada área de conhecimento, seja ela disciplinar, seja especializada ou não, precisam ser definidos e aceitos pela comunidade científica. O objetivo deste artigo é estabelecer parâmetros que possibilitem o reconhecimento dos limites e, conseqüentemente, as possibilidades de integração e de respeito à diferença que devem subsidiar a construção de objetos, métodos, paradigmas e linguagens próprias a diferentes campos do conhecimento nas ciências sociais.

\section{INTEGRATION AND DIFFERENCE IN INTERDISCIPLINARY ENCOUNTERS}

Myrian Sepúlveda dos Santos

Keywords: Interdisciplinary; Epistemology; Social theory; Sociology.

Scientific approaches build their objects based on proposals that can be related to social and political projects. Although interdisciplinary researches respond to an increasing social demand, they face obstacles because they both defy the knowledge that has been institutionalized and need new scientific paradigms. The limits of each new area of knowledge need to be defined and accepted by the scientific community. The aim of this article is the establishment of concepts that allow the scientific community to recognize different limits and, consequently, the possibilities of integration and respect to difference, which will be essential to the construction of different objects, methods, paradigms, and language within each new scientific field of the social sciences.

\section{INTEGRATION ET DIFFERENCES DANS DES RENCONTRES DISCI- PLINAIRES}

Myrian Sepúlveda dos Santos

Mots-clés: Interdisciplinarité; Épistémologie; Théorie sociale; Sociologie.

La science construit ses objets sur la base de propositions de savoir qui peuvent être liées à des projets sociaux et politiques. Malgré le fait que les recherches interdisciplinaires répondent à des demandes croissantes de la société, elles se heurtent à des difficultés aussi bien par le fait de défier le savoir disciplinaire établit, que par celui de demander de nouveaux paradigmes pour le savoir, ce qui, dans la plupart des cas, n'a pas lieu. Les limites établies par chaque domaine de savoir, soit-il disciplinaire, spécialisé ou pas, doivent être définies et acceptées par la communauté scientifique. L'objectif de cet article est d'établir des paramètres qui permettent la reconnaissance des limites et, en conséquence, les possibilités d'intégration et de respect aux différences qui doivent subventionner la construction d'objets, de méthodes, de paradigmes et de langages propres à différents domaines du savoir dans les sciences sociales. 